\title{
Developing High Schooler's Self-Directed Learning Ability Through the Online English Reading and Writing Program
}

\author{
You-Jin Jeong ${ }^{1}$ and Mun-Koo Kang ${ }^{2}$ \\ ${ }^{1}$ Department of English Education, Kongju National University, 56 Gonjudaehak- \\ Ro, Gongju-Si, Chungcheongnam-Do, 314-701, South Korea \\ ${ }^{2}$ Department. of English Education, Kongju National University, 56 Gonjudaehak- \\ Ro, Gongju-Si, Chungcheongnam-Do, 314-701, South Korea \\ ljeongyujin9844@hanmail.net
}

\begin{abstract}
The aim of this research was to develop an online English reading and writing program for Korean high school students who have time and space restrictions. This study reviews the following questions- first, does English education, by using online English reading and writing programs, improve students' self-directed learning? Second, does English reading education, by using online English reading and writing programs, change students' attitudes toward English reading? Third, does English writing Education, via online editing, change students' attitudes toward English writing? To test this, thirty 10th graders were observed to demonstrate that online English reading education positively influenced students' self-directed learning ability. Thirty students of the experimental group took part in the Online English Reading and Writing Program and thirty students were the control group and studied English in a traditional Korean class. The students wrote an essay about what they read and then they get feedback from foreign teachers. This could give the students motivation to try to express their ideas in English. Students can check their learning process and evaluate their learning skills by themselves. After the three-month experiment had passed, students got a survey. The survey consisted of assessing the students' attitudes toward English reading and writing, as well as the conditions of their self-directed learning ability (such as interest, confidence, motivation and study planning).
\end{abstract}

Keywords: Online English Reading and Writing Program, Self-directed learning ability

\section{Introduction}

The 21 st century is a period of globalization, information, and variety. The increasingly rapid social changes in the world require students to develop the ability to choose what they want to learn by judging the information provided. Knowledge now is not an absolute but is a relative process whereby learning happens by the students actively constructing the information through their experience. That's why students who actively participate in learning can learn school subjects, including English, better than the passive students. Self-directed learning ability means that learners themselves plan, implement, and achieve their outcome. In other words, this term includes self-planned learning, inquiry method, independent learning, self-instruction, autonomous learning and self-regulation learning. In self-directed learning, learners perform a daily task and should be prepared to deal with said task. Also, they are motivated to learn something by

Received (October 25, 2017), Review Result (January 25, 2018), Accepted (January 31, 2018) 
intrinsic stimulus, such as self-esteem or curiosity. Therefore, it is essential that selfdirected learning ability should be implemented.

I started this research with a faith that this online English reading and writing program could help the students to develop their self-directed learning ability.

The purpose of this research is to analyze the effect of online English reading and writing programs. The purposes include:

1. the influences of online English programs on self-directed learning ability.

2. to examine how much online based English reading and writing education influences high school students' affective attitude toward reading and writing.

The results concluded from this research will suggest an effective English writing education for high school students and provide relevant reading materials for the students. In addition, this research will suggest problematic implications about the current English writing education for high school students who solely focus on studying English for the Korean Scholastic Ability Test.

\section{Online English Reading Program}

\subsection{Preparation phase}

The Online English reading program is a process in which students do self-study English book reading and fill in a book report template. The distinctive feature is that students should set their own study plan and perform the plan during a given period of time by answering the questions of the template by themselves. Students who participate in the program are required to read three books and finish each template in 30 days. Each session takes the following steps. The researcher took several steps before implementing the program. Firstly, the researcher selected three books that took into consideration the students' interest and comprehension level. The books are usually about 150 pages, and are accessible using the online English library or as paperback copies. Secondly, the researcher designed a template which included an analysis of characters and plots about the story and open-ended question which could be helpful in writing an essay. The first part of the book report template included the time and place that the story happened. The analysis of character section presents the names of the main characters and has the students fill out the traits of the characters from the book. The plot questions section has four to five key questions regarding the beginning, development, climax and resolution of the story. Students also have to write down unknown words from the given book in the vocabulary section. The check-up questions require a kind of intensive reading ability. The questions are very specific and detailed. The students have to remember exact information from the story. The essay part has the students answer an open-ended question in about two to three paragraphs. This requires students to enhance their critical thinking abilities and connect the story with their own daily lives, which makes for a more authentic understanding of the book. Finally, the researcher accepted the students' applications online. Among the students, the researcher chose 40 students from those who applied for this program.

\subsection{Online English Reading Phase}

In this phase, students read the books online. Most of students have a smart phone or tablet PC which can access the Internet. The students were able to read English books as E-books through the website. They submitted the book reports anytime they wanted. Students are supposed to read one book per month, and three books in total, in a single semester. The researcher also provided paper books to the students since some of the students cannot use the internet. The students are given 30 days to read a book which has 140-200 pages. Online English reading positively influences students by expanding their 
background knowledge and instills sensitivity through reading various written English materials, not only the required textbooks. The distinctive feature of reading a book online is that the students feel more comfortable when they are reading. That's because it is not that serious or too academic. They can read English books when they have free time or while they are waiting for someone or for an appointment. Students easily absorb the English, similar to when they are reading a magazine online. It can be an extensive reading, which does not have any pressure on the result of an added exam or grading. This type of reading is pleasure reading, which is just for reading English for enjoyment.

\subsection{Online English Writing Phase}

Writing has been disregarded compared to reading and listening in the Korean English education system. However, in order to improve students' English proficiency, all the four language skills-speaking, listening, reading and writing- need to be emphasized. Writing should be fostered as a productive tool so that students can become more familiar with the sentence structure of the language. The online English writing phase is one in which students write a book report after reading a book and then upload it onto the homepage. The book report consists of analyzing characters, plot questions, vocabulary, check-up questions and an essay. During the process, students are able to find out related information in order to finish the template in English and they also have to use the MS word program. Some of the students find difficulty in using the MS word program, so Korean English teachers help and lead them so that they can finish their work. Students do not have to finish the assignment as a team; it is an individual assignment. By using their personal computers, they can choose what time and space they want to do it in. Thus, it overcomes the time and space limitations of students. Korean high school students have better reading than writing skills. That's because the Korean SAT is mainly testing the students' reading skills. So students can create simple and short sentences using learned vocabulary and structures to express what they want to say. Also they can write on familiar topics based on the school textbook. When it comes to reading a novel and writing an essay, due to insufficient knowledge of vocabulary or grammar, they may have difficulty in conveying the message they intend. The last part of this book report is to write an essay related to the given open-ended question. The purpose of this activity is for the students to write several short paragraphs in English and to try to organize their ideas using a variety of phrases and grammar forms. In this way, students will be encouraged to proceed through each sentence with pleasure and enjoyment.

\subsection{Online Feedback Phase}

Native teachers check and edit the grammar in the student's template and then write comments about the content and grammar. After the native teacher finishes giving the feedback, Korean teachers add more comments on the book report and essay. Once the feedback is completed, Korean teachers upload it onto the website as a reply form. Students get edited results and are able to learn their weak areas of grammar that they should study more, this leads to a better self-directed learning. This kind of online environment provides the place where students and teachers can use feedback as a means to learn language. Generally, an editing process between native teachers and students in the classroom is done one on one, but because there is only one native teacher in the class, other students have to wait without doing anything until their turn. An advantage of online feedback is that the students do not have to wait while the teacher edits and writes feedback. Moreover, students are able to specifically check their grammar and repeated grammar mistakes because feedback is presented in a written form. The feedback they receive online gives them opportunities to evaluate their work, and reflect on how it was received. Through the medium of online feedback, students have the opportunity to 
communicate with the teacher and this process builds a rapport between the students and the teacher. In addition, it helps the students to see their strengths by finding out what parts of their writing created confusion with their readers.

\section{Research Methodology}

\subsection{Participants}

The research subjects are 10th graders who study at an academic high school and live in $\mathrm{C}$ province. The experimental group consisted of the students who participated in the online English reading and writing program. The control group consisted of students who studied under normal school conditions. Both group members were a mixture of boys and girls. The size of each group was 30 students, with 60 students in total. All of the participants in this study belonged to the 10th grade with middle to high English level, therefore the experimental group and control group were at a comparable English level at the beginning of this study. To prove the same quality of the two groups, the researcher implemented an independence t-test before this experiment.

\subsection{Designing Experiment}

The objective set by this research is that an online based English reading and writing program influences 10th graders' ability of self-directed learning and improves their attitude toward English learning. There are three hypothesizes;

1. The online English reading and writing program will have the effect of improving the students' self-directed learning ability.

2. English reading education, using the online English library, will have an effect on changing the students' attitude toward English reading.

3. English writing education, through the online English correcting, will have an effect on changing the students' attitude toward English writing.

This research was conducted in the fall semester of 2015. It took four months. The presurvey was conducted on the first day of the research. For three months, the students in the control group took traditional reading and writing classes at school. The experimental group members were involved in the online English reading and writing program. The students were required to complete three monthly book reports, which included writing the book report and reading the given book. Data sources from this research were from the pre-survey tests and post-survey tests.

\subsection{Survey Results}

The test results were processed using SPSS. A post-survey, identical to the pre-survey, was given to the students on the last day of the program. Variations in the students' answers from the pre and post-survey tests were examined and correlated to compare and contrast changes from the two tests. The statistical Package for the Social Sciences(SPSS) was used to analyze survey data by calculating the t-test to determine if the pre and post survey test results were significantly different from each other. The average indicates the average of the total score of the survey test. $\mathrm{N}$, is the total number of students, $\mathrm{T}$ is the statistical hypothesis test used to determine if the pre and post test data are significantly different from each other. Using a 95\% confidence interval, if the results are less than 0.05 , it is considered to have a significant change. It can be concluded that the comparable significant of .00 of the pre and post-test survey results shows significant increase in overall self-directed ability, as well as students' overall attitude toward English reading and writing. Post survey results reveal increases in students' attitude toward English reading and writing among the experimental group. It 
can be assumed that the online English reading and writing program gave the students a chance to develop a positive attitude towards the study of English. Students' attitude toward English reading and writing shows a slightly positive improvement. That's because online English reading has some advantages. First, the students read an interesting story which had a plot. The students could be a reader who envisions themselves in the main character struggles. That attracts students' interest and boosts their imagination. Secondly, online English library offers abundant reading materials and the students can easily get books according to different genres or levels of difficulty. Students can select what they want to read, other than the textbooks which teachers give, and this causes them to develop a good reading habit. This leads to not only reading comprehension but also overall language acquisition. Thirdly, students have an acquisition of a new method of learning English. Also, the online books are continually updated. Learners who are flexible and extroverted usually prefer to receive online learning.

Online writing provides students with the time to think deeply about the topic. In classroom situations, students have to complete assignments in limited time and that's not good for critical thinking. Students are pressured to submit their task to the teacher and that also doesn't guarantee a good quality. Also the open-ended essay questions on the online book report are mainly about the students' own experience. This can be a bridge to connect English writing with the students' lives. In addition, the online feedback focused on grammar, spelling, and mechanics. After getting the teacher's feedback, the students critically examine it and figure out their strengths and weaknesses in writing. Students who are introverted and individualized-oriented prefer this method because they don't have to show their weak points in public and they easily understand which part should be revised and changed. Post survey results reveal increases in self-directed learning ability among the experimental group. It can be assumed that the online English reading and writing program gave the students a chance to develop a willingness to study English on their own.

\section{Conclusions}

The researcher believes that the online English reading program will improve student's self-directed learning ability and maximize learning effects. The program is processed in 4 steps; preparation, online reading, online writing and online feedback. First, the preparation stage is for teachers to make book report templates and gather students for controlled and experimental groups. Secondly, online reading is a period which students read English books online. Thirdly, online writing is a period in which students write a book report. Finally, online feedback is for the teachers to give comments and grammar corrections. To determine whether the 4 steps positively influence an improvement of self-directed learning for the students, the researcher set three hypothesizes; 1 . Will the online English reading and writing program improve the students' self-directed learning ability? 2. Whether reading education using online English library will affect the students' attitude toward English reading? 3. Whether English writing education through online English correcting will affect the students' attitude toward English writing?

To verify the three hypothesizes, the researcher implemented t-verification of an independent sample. Results are: First, there was a meaningful difference before and after the online English reading program. This indicates that the students actively participated in learning activities by self-adjusting their pace of study. Second, the online English reading program indicates that the students became more interested in English reading and this leads to active participation in learning. Third, students put more effort in the book reports over assignments from their regular classes. It is hoped that this research can raise awareness about the importance of using the online program and have a positive 
effect on reading and writing instruction for Korean EFL students.

\section{References}

[1] H. D. Brown, "Principles of language learning and Teaching (5th Ed)", New York: Pearson Education, (2007).

[2] M.: Gibbons, The self-directed learning handbook LA: John Wiley \& Sons, Inc. (2002).

[3] A. Heyde, "Teaching English as a second or foreign language", Boston: Haninle \& Heinle, (1979).

[4] Y.-J. Jeong and M.-K. Kang, "The Effects of Online English Reading Program on a Self-directed Learning Ability”, Proceedings of the 127th In Advanced Science and Technology Letters, Jeju, Korea, (2016).

[5] M.S. Knowles, "Self-directed learning: A guide for learners and teachers", Chicago, IL: Association Press, (1975).

[6] H.B. Long, "Self-directed learning application and research", Norman, OK: Research Center for Continuing Professional and Higher Education of the University of Oklahoma, (1992). 